the primary affection. Should they, how-/dressing-gown, and allow him to take my ever, prove obstinate, then they must be place on the bed, that the operation might regarded as more independent affections, be immediately performed on him. In and the treatment of them as such, does vain did I appeal to my state of debility as not properly come within the scope of a reason for a few days delay. "I had these observations, nor would the limits merely," he said, "to introduce the instrunecessary to this paper permit its in-ment, find his foe, and crush it. He troduction. was sure that I could do it in three mi-

of course it is unnecessary to remind nutes, and he could then return home practitioners, that the state of the bowels, happy."

skin, \&c., should receive the usual atten- I could no longer resist his entreaties, tion, and any deviation from the healthy and although it seemed almost ludicrous condition should be duly attended to. to undertake the operation under such Upon the whole, I think that they who will circumstances, I consented. I dressed give the plan of treatment here recommended a fair trial, will have but little occasion to be dissatisfied with the results of their practice.

London, May 3rd, 1833.

\title{
LITHOTRIPSY.
}

myself while he undressed, and we changed places. The injection of the bladder, the introduction of a small slide percussor, the seizing and crushing of the stone, which was small, did not occupy three minutes. When held in the instrument, it measured somewhat more than half an inch in diameter. I had the satisfaction of seeing him void a large portion of it before he left the room. On the next day he felt assured that the entire stone had been voided, and I examined him again before he left town, and could discover no remaining portion. Since his return home

WHEN lithotrity was first introduced into England, it was predicted, that in consequerice of its adoption in mild cases, the severe cases of stone in the bladder would become less and less frequent, and that in proportion as persons suffering from this disease made early application for relief, would the operation of lithotrity itself be light, rapid, and comparatively painless. This prediction begins to be fulfilled.

The week before last, a gentleman came to me from Essex, who was all impatience to be reliered from a small stone, which he had had in his bladder for, he believed, a few months. He considered every day that he delayed having the operation performed, was adding to the improbability of ultimate cure. He talked of inflammation setting in, of the stone augmenting in size, of the bladder thickening; in a word, from reading on the subject, his imagination was haunted with the dread of those morbid changes which sometimes mar the operation of lithotrity, and which are induced by the sojourn of the stone in the bladder for a considerable number of years. When he came to London, I was suffering from an attack of the influenza, and confined to my bed. But this was not a sufficient excuse with him for a postponement of the operation, even for a few days. He was miserable in mind and hody, and said that he must see me. At last I received him in my bed-room, when he described his case, and finished by urgently is, that it was not a method of treatment requesting that I would rise, put on my originating with $\mathrm{Mr}$. Earle; for Mr. Ste-

\section{SUBSTANCES IN THE AUDITORY PASSAGES.}

\section{To the Editor of THE LANCET.}

SrR,-About thirteen years ago, Mr. Henry Earle presented a paper to the Medico-Chirurgical Society, giving the case of Mr. Farr, who, according to Mr. Earle's account, was cured by a mode of practice which he, Mr. Earle, had adopted. The disease was " occasional inflammation of the external ear, accompanied with heat, excoriation, and a copious thin discharge from the passage, which affected his hearing, more or less, for several weeks, but left no permanent deafness behind." Mr. Earle "dilated the passage with a little instrument which he had constructed for the purpose of examining the external meatus," and then applied a strong solution of nitrate of silver, until he had detached and brought away the whole cuticular lining of the meatus externus, together with that portion of it which is reflected over the membrana tympani; and this treatment Mr. Earle claimed, apparently, as an original idea of his own, and 
venson had adopted the same method for a considerable period previously, so frequently, and at the same time so unsuccessfully, that up to the time Mr. Earle wrote, I had had at least one hundred patients to whom it had been applied by Mr. Stevenson, without producing the least advantage. In a work I published in 1820 , I condemned the practice, not only as useless, but as being likely to make the patient, eventually, incurable. The case of the Duke of Wellington, who had been attended by Mr. Stevenson, fully proved the justice of my remarks, and the method adopted by me restored his Grace's right ear to such a perfect state, that he scarcely feels the loss of the function of his left ear, the sense of hearing in which is utterly destroyed.

$\mathrm{It}$ is a subject of regret, that Mr. Henry Earle did not use the " little instrument which he had constructed for examining the external meatus," in the case of the poor child Thomas Brady, who, according to the report in your 380 th Number, p. 380, was operated on in St. Bartholomew's Hospital, and eventually lost his life, by the endeavours of Mr. Earle to extract a nail from the ear, which the most careful post-mortem examination even into the cochlea, semicircular canals, vestibule, and mastoid cells, failed to discover!!!

Great allowance should be made for the difficulty of keeping the head of a child quiet, especially after he had had the pain of a probe in his car; but I never found a child, or adult, whom I could not, by the exercise of a little patience, induce to sit perfectly still, so as to allow me to inspect the meatus most completely, for as my method gives no pain, 1 encounter none of the difficulty which, as I learn, attends other modes of examination. **** *

I am, Sir, your obedient servant,

W. Wright, Surg. Aurist.

\section{8, Sackville-Street, Piccadilly,} April 29, 1833.

Dry CUPPING.-A lady of rank, living near Dublin, was occasionally attacked by violent determination of blood to the bed, and each of the paroxysms was sure before it ended to induce a violent propensity to suicide. This congestion and propensity were afterwards removed, or rather prevented, by the timely application of dry cupping as soon as the well-known premonitory symptoms of the paroxysm appeared.-Dr. Graves. Dub. Jour.

it The incertion of the coneluding paragrath would subject us to an action tor libel - lib. L.
PROTO-IODURET OF MERCURY IN

SECONDARY SYPHILIS.

To the Edilor of TIE Lancet.

Srr, - The following account of the effects of the proto-ioduret of mercury in secondary syphilis, may induce English practitioners to give this valuable remedy a trial. I am, Sir, your obedient servant, C. F.

M. Biett was one of the first who gave the proto-ioduret a trial in diseases of the skin and in secondary symptoms. The original idea belonged to Professor Odier, of Geneva. Only three cases out of 150 resisted this mode of treatment ; yet they had proved rebellious to every other means, although sedulously employed. It has been successful in very old, inveterate cases, where the dermoid, mucous, and osseous systems, were simultaneously involved. In the case of Alphonso C., ætat. 70, the disease was of very old standing, and returned several times, with different symptoms. $\mathrm{He}$ had grey jagged ulcers, with bands running across them, and callous edges; the os frontis carious, with a deep fissure to the right orbit. This man tried the proto-ioduret as a last resource. We were astonished to perceive at the end of six weeks, that the ulcers lost their grey colour and callous edges, and cicatrized, although irregularly, still solidly. The fissure so healed, that it was impossible to say that exfoliation of the os frontis existed. The success was not less remarkable in sereral other cases which had previously resisted the most skilfullyapplied treatment.

A very remarkable case, attended by M. Biett and M. Miguel, was that of a man affected with a tubercular form; the entire body was corered. He denied ever having had primary symptoms. After using the proto-ioduret one month, the tubercles faded, leaving a slightly livid trace.

The dose may be one grain daily for thirty or forty days, or, in severe cases, four grains, where there is no irritability of the digestive organs. Sometimes a puffiness of the gums was observed, but nerer ptyalism. It should be continued for some days after the eruption disappears. No relapse occurred. Ulcers of the pharynx and velum palati quickly heal by its external application. M. Biett attended a woman, whose entire throat and velum palati was ulcerated and her tongue fissured. It resisted all other means, but yielded to the application of the proto-ioduret several 